\title{
Anti-cancer activities of Ganoderma lucidum: active ingredients and pathways
}

\section{Chi H.J. Kao1, Amalini C. Jesuthasan", Karen S. Bishop ${ }^{2}$, Marcus P. Glucina ${ }^{3}$, and Lynnette R. Ferguson ${ }^{1,2,4}$}

${ }^{1}$ Discipline of Nutrition, FM\&HS, University of Auckland, Auckland 1142, New Zealand;

${ }^{2}$ Auckland Cancer Society Research Centre, FM\&HS, University of Auckland, Auckland 1142, New Zealand; ${ }^{3}$ Great Navy Ltd, Manuwera, Auckland, New Zealand; ${ }^{4}$ Nutrigenomics New Zealand, University of Auckland, Auckland 1142, New Zealand

Submission date: December 3, 2012; Acceptance date: February 8, 2013; Publication date:

February 9, 2013

\section{ABSTRACT}

Ganoderma lucidum, commonly referred to as Lingzhi, has been used in Asia for health promotion for centuries. The anti-cancer effects of G. lucidum have been demonstrated in both in vitro and in vivo studies. In addition, the observed anti-cancer activities of Ganoderma have prompted its usage by cancer patients alongside chemotherapy.

The main two bioactive components of $G$. lucidum can be broadly grouped into triterpenes and polysaccharides. Despite triterpenes and polysaccharides being widely known as the major active ingredients, the different biological pathways by which they exert their anti-cancer effect remain poorly defined. Therefore, understanding the mechanisms of action may lead to more widespread use of Ganoderma as an anti-cancer agent.

The aim of this paper is to summarise the various bioactive mechanisms that have been proposed for the anti-cancer properties of triterpenes and polysaccharides extracted from $G$. lucidum. A literature search of published papers on NCBI with keywords "Ganoderma" and "cancer" was performed. Among those, studies which specifically examined the anti-cancer activities of Ganoderma triterpenes and polysaccharides were selected to be included in this paper.

We have found five potential mechanisms which are associated with the anti-cancer activities of Ganoderma triterpenes and three potential mechanisms for Ganoderma polysaccharides. In addition, G. lucidum has been used in combination with known anti-cancer agents to improve the anti-cancer efficacies. This suggests Ganoderma's bioactive pathways may compliment that of anti-cancer agents. In this paper we present several potential anti-cancer mechanisms of Ganoderma triterpenes and polysaccharides which can be used for the development of Ganoderma as an anti-cancer agent.

Keywords: Ganoderma lucidum, cancer, bioactive pathways, triterpene, polysaccharide 


\section{INTRODUCTION:}

Ganoderma lucidum (G. lucidum), commonly referred to as Lingzhi in China, is a fungus which has been widely used through the centuries for the general promotion of health and longevity in Asian countries. It has been known to have numerous pharmacological effects including immuno-modulating, anti-inflammatory, anti-cancer, anti-diabetic, anti-oxidative and radicalscavenging, and anti-aging effects [1].

Most mushrooms are $90 \%$ water by weight. For G. lucidum, the remaining $10 \%$ consists of 26-28\% carbohydrate, $3-5 \%$ crude fat, $59 \%$ crude fibre, and 7-8\% crude protein [2]. In addition, G. lucidum contains a wide variety of bioactive constituents such as terpenoids, steroids, phenols, glycoproteins, and polysaccharides [3, 4]. Numerous authors have shown that triterpenes and polysaccharides are the major physiologically active components of G. lucidum $[3,4]$.

In this review, we focused on the various bioactive pathways thought to be associated with the anti-cancer activities of $G$. lucidum, in particular, the two main active ingredients: triterpenes and polysaccharides.

\section{Triterpenes}

Triterpenes are one of the possible pharmaceutically active compounds contributing to the medicinal activities of G. lucidum [5,6]. Triterpenes are a subtype of Terpene, a class of naturally occurring compounds, composed of one or more isoprene units. Terpenes are widely distributed throughout the plant world. Many subtypes of Terpenes have been found to have antiinflammatory, anti-tumourigenic, and hypolipidemic activity [7]. Triterpenes contain six isoprene units. The isoprenes may form linear chains or fold-up and form a ring-like structure. Ganoderic acid is a sub-type of triterpenes with four cyclic and two linear isoprenes. There are over 140 species of triterpenes and triterpenoids identified in G. lucidum [8].

Triterpenes are primarily isolated from the spores of G. lucidum and have shown remarkable pharmacological and therapeutic activities on multiple human diseases including cancer $[5,6]$. Extraction of triterpenes is usually by means of methanol, ethanol, acetone, chloroform, ether, or a mixture of these solvents [9].

Studies have shown that many subtypes of triterpene extracts from G. lucidum can directly induce apoptosis of multiple human cancer cell lines [5]. The cytotoxic effect varied greatly between different subtypes of triterpenes [5]. Some subspecies of triterpenes have shown strong cytotoxic effects at low concentrations in various human cancer cell lines, these include:

Ganoderic acid $\mathbf{T}$ is the most abundant triterpenic acid found in G. lucidum and shows significant anti-cancer effects in both in vitro and in vivo studies [10,11, 12]. In a study by Chen et al. (2010), Ganoderic acid T was shown to inhibit tumour invasion by inhibiting Matrix Metalloproteinase (MMP)-9 expression [10]. Ganoderic acid D has been shown to directly bind

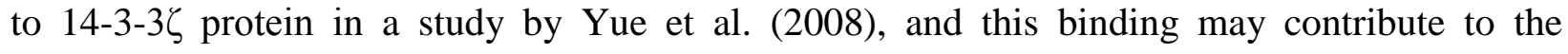
apoptosis observed in HeLa cell [13]. Ganoderiol F (GA-F) is a tetracyclic triterpene found in Ganoderma species $[14,15]$. GA-F has shown cytotoxicity in vitro against Lewis lung carcinoma (LLC), Meth-A, Sarcoma-180, and T-47D cell lines [15, 16]. In addition, the anti-tumour effect of GA-F has been demonstrated in vivo in rats implanted with LLC tumour cells [17]. Additional 
forms of triterpenes isolated from G. lucidum have shown cytotoxicity in the following human cancer cell lines: p388, HeLa, BEL-7402, and SGC-7901 [18, 19].

There are several mechanisms by which triterpenes contribute to the anti-cancer activities of G. lucidum as shown in Figure 1:

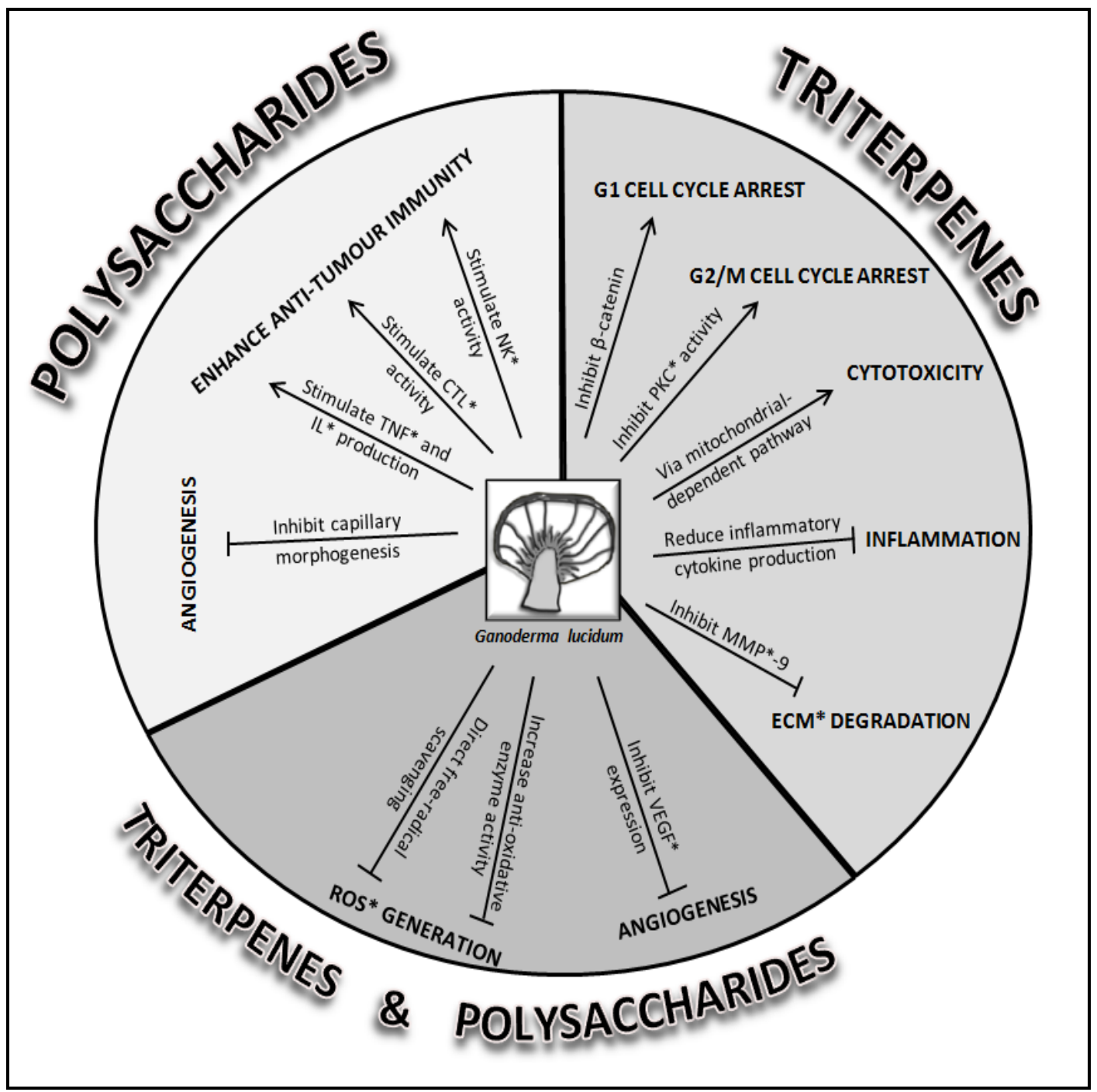

Figure 1: An overview of anti-cancer pathways affected by the triterpenes and polysaccharides from $\boldsymbol{G}$. lucidum [*CTL Cytotoxic T-lymphocytes; ECM Extracelluar matrix; IL Interleukin; MMP matrix metalloproteinase; NK Natural killer cells; PKC Protein Kinase C; ROS Reactive oxygen species; TNF Tumour necrosis factor; VEGF Vascular endothelial growth factor]

\section{Cell cycle arrest}

Cancer cells have a deregulated cell cycle leading to uncontrolled cell proliferation. Anti-cancer agents can arrest the cell cycle at $\mathrm{G} 0 / \mathrm{G} 1, \mathrm{~S}$, or G2/M phase, reducing the rate of proliferation [20]. Studies have shown that triterpene extracts from G. lucidum can arrest the cell cycle at the G1 phase [21, 22]. The likely mechanism of action for cell cycle arrest at the G1 phase is through the down-regulation of Cyclin D1 via modulation of the B-catenin pathway [23]. Cyclin D1 is a regulator of Cyclin Dependent Kinase (CDK) which is crucial for G1/S transition in the cell 
cycle [24]. The Cyclin D1 promoter contains transcription factor (TCF)/Lef-binding sites which can be activated by $\beta$-catenin/Lef-1/TCF [25]. Approximately $30 \%$ of colon carcinoma cells have an over-expression of Cyclin D1 as a result of abnormal B-catenin signalling [26]. Ganodermanontriol, a G. lucidum triterpene extract, inhibits proliferation of colon cancer cells HCT116 and HT-29 by inhibiting the expression of B-catenin [22].

In addition to cell cycle arrest at the G1 phase, triterpene extracts can also inhibit cells at the G2/M transition [27]. Treatment with triterpene-enriched ethanol soluble fractions (WEES-G6) can suppress the activity of protein kinase $\mathrm{C}$ (PKC), leading to a prolonged $\mathrm{G} 2$ phase. PKC is a class of serine-threonine protein kinases that is selectively activated during the $\mathrm{G} 2$ phase of the cell cycle [28]. PKC is involved in the regulation of nuclear lamina disassembly during the G2 phase [29]. Studies have shown that the use of PKC inhibitors can also cause cell cycle arrest at the $\mathrm{G} 2$ phase $[30,31]$. In addition, WEES-G6 can reduce the level of Cyclin B, a kinase which is crucial for the transition from G2 to M phase [27]. WEES-G6 also activates c-Jun N-terminal kinase (JNK) and p38 kinase, both of which are mitogen-activated protein kinases (MAPK) which respond to cellular stress [27]. JNK is a critical regulator of transcription and can activate tumour suppressors such as p53 [32, 33, 34]. To further support the use of triterpenes as a therapeutic anti-cancer agent, Johnson and Lapadat. (2002) observed cell cycle arrest in triterpene-treated HuH-7 human hepatocellular carcinoma but no effect was seen in a normal human liver cell line [32]. In order to find the cause of the triterpene-induced G2 phase cell cycle arrest, Li et al. (2005) identified the inhibition of DNA synthesis via inhibition of topoisomerase as the likely cause of Ganoderic acid X- induced cell cycle arrest [35].

\section{Cytotoxicity}

Cytotoxic compounds can also directly trigger apoptosis leading to programmed cell death [36, 37]. Studies have shown that triterpenes induce apoptosis in human cancer cell lines via a mitochondria-dependent pathway, followed by activation of the caspase cascade [38, 39].

The intrinsic apoptotic pathway, also known as the mitochondria-dependent apoptotic pathway, involves decreasing the mitochondrial potential, followed by the release of cytochrome c from the mitochondria $[40,41]$. The release of cytochrome c into the cytosol triggers the caspase cascade leading to apoptosis. The caspase cascade includes caspase 9 and caspase 3 which are found to have elevated expression in human cancer cells treated with G. lucidum triterpenes [11, 42].

The release of cytochrome $\mathrm{c}$ from mitochondria is dependent on the permeability of the mitochondrial outer membrane which is closely regulated by the B-cell lymphoma 2 (Bcl-2) family proteins [43]. The Bcl-2 family proteins can either be pro-apoptotic or anti-apoptotic. Bcl2 is anti-apoptotic while Bcl-2-associated X protein (Bax) and Bcl-2-associated death promoter (Bad) are pro-apoptotic. The ratio of Bax/Bcl-2 balance determines the release of cytochrome $\mathrm{c}$ after apoptotic stimulus [44]. Increasing the ratio of Bax/Bcl-2 promotes apoptosis. Studies have shown that treatment with $G$. lucidum triterpenes increases the ratio of Bax/Bcl-2 in human cancer cells by increasing Bax expression while down-regulating Bcl-2 expression [42]. However, different subtypes of triterpenes have different effects on Bax and Bcl-2. In a study by Tang et al. (2006) treatment with Ganoderic acid T was shown to up-regulate Bax expression while Bcl-2 expression remained unchanged [11]. 
The 14-3-3 proteins are a family of conserved regulatory proteins, they are involved in many cellular process including cell cycle progression and apoptosis via regulating protein kinase signalling cascades [45]. A target of 14-3-3 protein is the Bad pro-apoptotic protein. Binding of the 14-3-3 protein to Bad inhibits Bad-induced cell death [46]. Studies have shown that Ganoderic acids can directly bind to 14-3-3 protein thus inhibiting its activity [13, 39].

\section{Reduced metastatic potential}

Cancer metastasis is a complex process by which cancer cells split from the primary tumour and invade other tissues and thereby form secondary tumours. Cancer metastasis, when left untreated, dramatically reduces the rate of cure and survival. There are several key proteins involved in cancer metastasis which may be regulated by G. lucidum triterpenes.

Matrix Metalloproteinase is a family of proteins that degrade the extracellular matrix and can promote cancer metastasis [47]. Studies showed that Ganoderic acid extracted from $G$. lucidum suppressed invasion of 95-D, LLC, and HCT-116 metastatic cancer cells via inhibition of MMP-9 expression [48, 49].

Interleukin (IL)-8 and other angiogenic factors such as vascular endothelial growth factor (VEGF) can induce angiogenesis and promote metastasis [50]. Expression of IL-8 can be upregulated by oxidative stress and overexpression of IL-8 is associated with the metastatic phenotype of breast cancer cells $[51,52]$. Oxidative-induced IL-8 expression was reduced in a breast cancer cell line after treatment with G. lucidum [53].

\section{Anti-Inflammation}

Inflammation has been linked as a causal agent in $\sim 20 \%$ of cancers $[54,55]$. Chronic overexpression of inflammatory cytokines such as VEGF, IL-6, and tumour necrosis factor (TNF)- $\alpha$, can promote carcinogenesis [56, 57]. Dudhgaonkar et al. (2009) have shown that administration of G. lucidum triterpene extract suppressed inflammatory cytokine secretion in macrophage cells thus decreasing the level of inflammation [58].

\section{Anti-oxidant}

Oxidative stress is known to be a major contributor to increased cancer risk. Free radicals and reactive oxygen species (ROS) are generated as by-products of metabolic processes involving redox enzymes and bioenergetics electron transfer, and exposure to some exogenous chemicals [59]. Free radicals and ROS can damage proteins and DNA within cells leading to oxidative stress, which can be countered by anti-oxidative enzymes and repair mechanisms. However, excess oxidative stress can overwhelm the innate protective systems leading to a variety of physiological disorders including cancer [59]. Cancer cells generate increased levels of free radicals relative to normal cells, further contributing to cancer progression [59]. More and more evidence suggests that this cancer-inducing oxidative damage might be prevented or limited by using anti-oxidants. Anti-oxidants may mediate their effect by directly reacting with ROS, quenching them or chelating the catalytic metal ions [60].

Smina et al. (2011) showed that triterpenes extracted from G. lucidum have anti-oxidative properties in vitro and can reduce oxidative damage by directly scavenging free radicals generated in the cell [61]. In addition, administration of triterpenes to mice increased the 
activities of anti-oxidant enzymes and reduced radiation-induced oxidative DNA damage in mice splenocytes [61, 62]. The ability of triterpenes to scavenge free radicals and enhance innate antioxidant enzymes indicates that triterpenes are a highly efficient anti-oxidant.

\section{Polysaccharides}

Polysaccharides are long chain sugar molecules joined together by glycosidic bonds. Various types of polysaccharides, with molecular weights ranging from $4 \times 10^{5}$ to $1 \times 10^{6}$ Da have been identified in G. lucidum; mostly in the fruiting body and mycelia, and a few have been found in the spores [1].

Structural analysis shows that polysaccharides of G. lucidum are all heteropolymers [63]. Glucose forms the major share of the sugar molecules; with xylose, mannose, galactose, and fucose in different conformations. It is hypothesised that the polysaccharides extracted from different parts of G. lucidum induce different immune responses with varying immune potencies [63]. The different branching conformation and solubility characteristics affects the antitumourigenic properties of these polysaccharides [64]. $\beta$-D-glucans consisting of (1-3)-, (1-4)and (1-6)- $\beta$-D linkages are known to have a stronger anti-tumour potency and better absorption than other polysaccharides in G. lucidum [64].

Together with the high concentration of high molecular-weight polysaccharides, the mushroom also consists of a matrix of the polysaccharide chitin, which is largely indigestible and is partly responsible for the physical hardness of the mushroom [65].

There are three mechanisms by which Ganoderma polysaccharides exert their anti-cancer effect as shown in Figure 1:

\section{Improve Immune Response}

In contrast to triterpenes, numerous studies have shown that polysaccharides exert their anticancer effect by enhancing the host's immune system rather than via a direct cytotoxic effect [66, $67,68]$. This involves the stimulation of macrophages, natural killer (NK) cells, and cytotoxic Tlymphocytes (CTL) activities along with their secretory products like TNF, reactive nitrogen and oxygen intermediates, and interleukins [69]. In a study performed by Wang et al. (1997), it was shown that polysaccharides extracted from the fresh fruiting bodies of G. lucidum can stimulate the production of IL-1 $\beta$, IL-6, TNF- $\alpha$, and interferon- $\gamma($ IFN- $\gamma)$ in human monocyte-macrophages and T-lymphocytes [68].

It is widely known that macrophages play an important role in many primary defence mechanisms via phagocytosis and secretion of immune cytokines in response to microenvironmental signals [70, 71]. The G. lucidum immune-modulating substance, (a proteoglycan isolated from the fruiting body of G. lucidum), activate bone marrow-derived macrophages in a dose-dependent manner. These activated macrophages showed a marked increase in their phagocytosis activity and increased production of IL-1 $\beta$ and nitric oxide [72].

The Major Histocompatibility Complex (MHC) is a type of protein expressed on all cell surfaces. The main function of MHC is to display a molecular fraction of proteins that are formed within the cell, a process known as antigen presentation [73]. Cancer cells, which have abnormal proteins or changes in amount of protein expression, can be detected by immune cells via antigen presentation which leads to CTL mediated apoptosis. Cancer cells may reduce the 
expression of MHC molecules to escape CTL mediated apoptosis [74]. NK cells can detect and induce apoptosis of cancerous cells with low MHC expression [75].

Fraction-3 (F3), a fucose-containing glycoprotein extracted from G. lucidum, stimulated the proliferation of murine spleen cells and expression of various cytokines, including IL-1, IL-2, and IFN- $\gamma$ [76]. A study by Chien et al. (2004) showed that F3 treatment of mononuclear cells extracted from human umbilical cord blood stimulated their differentiation into macrophages and NK cells by 2.9 and 1.5 times respectively [77]. Another study showed that an F3-treated human acute monocytic leukemia (THP-1) cell line exhibited enhanced macrophage differentiation via caspases and p53 activation [78]. This differentiation was demonstrated by changes in cell adherence, cell cycle arrest, increase in the expression of differentiation markers, and downregulation of myeloperoxidase (MPO) [78]. The enzyme MPO is synthesized only in myeloid and monocytic cells and the down-regulation of MPO activity is a characteristic feature in macrophage differentiation [79].

These results showed that polysaccharides obtained from G. lucidum could effectively increase the cellular immune activity in-vitro as well as in-vivo, by modulating cytokine production.

\section{Anti-oxidative Activity}

$\mathrm{Lu}$ et al. (2001) showed that dietetic treatment using a Ganoderma mycelium-derived polysaccharide extract can be used to suppress the formation of colonic aberrant crypt foci in rats, possibly via reducing the oxidative damage induced by ROS [80, 81]. In addition, an aminopolysaccharide fraction of G. lucidum called 'G009' inactivates hydroxyl radicals and superoxide anions and reduces DNA strand breaks in a dose-dependent manner [82]. This study showed that G009 inhibited the iron-induced lipid peroxidation in rat brain homogenates and showed a dosedependent inactivation of hydroxyl radicals and superoxide anions. It also reduced the strand breakage in DNA caused by UV-induced photolysis in differentiated HL-60 (human promyelocytic leukaemia) cells [82].

\section{Suppression of Angiogenesis}

Angiogenesis is a physiological process involving the development of new blood vessels from pre-existing vessels. The normal regulation of angiogenesis is governed by a fine balance between factors that induce the development of blood vessels and those that inhibit this process. A disruption of this balance leads to pathological angiogenesis. Tumour cells are known to induce angiogenesis by secreting various growth factors such as VEGF which induce capillary growth into the tumour, supplying it with required nutrients and allowing for tumour expansion and metastasis.

Studies have shown that G. lucidum possesses anti-angiogenic activity and can also inhibit the production of nitric oxide, an inducing agent of angiogenesis overexpressed in tumours [83]. A study by Cao et al. (2006) showed that a polysaccharide peptide (Gl-PP) isolated from $G$. lucidum inhibits the proliferation of human umbilical cord vascular endothelial cells (HUVEC) in a dose-dependent manner [84]. In human lung carcinoma cells, a high dose of Gl-PP for 18 hours under hypoxic conditions led to a decrease in the amount of secreted VEGF. In HUVECs, $G l$-PP led to a reduction in Bcl-2 expression and an increase in Bax expression which induces 
apoptosis in vascular endothelial cells. Therefore, Gl-PP may inhibit angiogenesis via inhibiting secretion of pro-angiogenic factors and inhibition of vascular endothelial cell proliferation [84]. It is possible that the cytotoxicity effect and the inhibition of proliferation observed in both polysaccharide and triterpene extracts may have the same bioactive pathways.

A study by Stanley et al. (2005) found that G. lucidum prevents capillary morphogenesis, an important step in angiogenesis associated with the growth and progression of cancer [85]. $G$. lucidum significantly inhibited capillary morphogenesis by inhibiting the secretion of angiogenic factors VEGF and Transforming Growth Factor (TGF)- $\beta 1$. G. lucidum was shown to inhibit prostate cancer angiogenesis by modulating MAPK and Protein Kinase B signalling and altering the phosphorylation of extracellular signal-regulated kinases 1/2 and Akt kinases [85].

\section{Extraction Methods}

The whole spores, fruiting bodies and cultivated mycelia of G. lucidum as well as its triterpenes and polysaccharides extracts have been widely tested for their various anti-tumour properties. Different sources of $G$. lucidum and varying extraction procedures to obtain the required components have been used in various studies. The extraction process is a necessary step to purify the mushroom by eliminating unnecessary components that are produced by the mushroom's natural growing process, while preserving the essential bioactive components within it. Numerous means of extraction have been developed with the objective of obtaining extracts with better yields and lower costs [86].

Generally, most polysaccharides are extracted using water-extract-alcohol precipitation methods $[87,88]$. The solubility and extraction efficiency in water depends on the molecular weight of the polysaccharide and water temperature, with lower molecular weight and hot water showing increased efficiency [89]. However, this method has its disadvantages such as reduced yields, long extraction time and high extraction temperature, and hence new technologies are being developed to overcome these drawbacks. Novel technologies using ultrasound, microwave and enzymatic methods have recently been developed to increase the yield in shorter extraction times [87].

Extractions using ethanol have been reported to be the easiest approach to maintain the activity of the triterpene extracts and to scale up its production [90]. Triterpenes are usually extracted using organic solvents such as methanol, ethanol, chloroform or ether followed by different separation methods [89]. Ultrasonic techniques are currently being used to enhance the rate of extraction of triterpenes by destroying the dense structure in the cells [87].

There are, however, very few studies comparing the different extraction procedures on the effectiveness of the individual bioactive components. However, a study by Lu et al. (2004) examined the ethanol and water extracts from fruiting bodies and spores of the G. lucidum using the MTT (3-(4, 5-dimethylthiazolyl-2)-2,5-diphenyltetrazolium bromide) cell proliferation assay and the resulting IC50s are shown in Table 1 [91].

Tong et al (2009) made a comparison of the cytotoxic activity induced by G. lucidum fruiting-body extracts obtained by hot water and methanol extraction methods. Results showed that methanol extraction produced a two-fold increase in cytotoxic activity in J558 (Balb/C mouse Myeloma) cells [92]. 
Table 1: Comparison of water and ethanol extracts from G. lucidum fruiting bodies and spores. (adapted from [91])

\begin{tabular}{|c|c|c|}
\hline Ganoderma lucidum Extract & Cell Line* & 24 hours $\mathrm{IC}_{50}(\mu \mathrm{g} / \mathrm{ml})$ \\
\hline Fruiting Body Ethanol Extract & HUC-PC & 325 \\
\hline Fruiting Body Water Extract & HUC-PC & 1000 \\
\hline Spore Ethanol Extract & HUC-PC & 521 \\
\hline Spore Water Extract & HUC-PC & 362 \\
\hline Fruiting Body Ethanol Extract & MTC-11 & 129.3 \\
\hline Fruiting Body Water Extract & MTC-11 & 509 \\
\hline Spore Ethanol Extract & MTC-11 & 274.7 \\
\hline Spore Water Extract & MTC-11 & 365.4 \\
\hline
\end{tabular}

*HUC-PC: human uroepithelial cell line MTC-11: Low-grade bladder cancer cell line

This shows that the organic solvent, rather than the water extraction method, has a stronger cytotoxic activity on cancer cells. Triterpene is the main active ingredient extracted from organic solvent, and polysaccharide is the main active ingredients extracted from water. This suggests that triterpenes may have a stronger cytotoxic effect than polysaccharides. However additional comparative studies using different cell lines need to be carried out to confirm these data.

\section{Ganoderma lucidum in combination with other cancer treatments}

Radiation therapy is commonly used in the treatment of cancer in order to damage the DNA of tumour cells, to inhibit proliferation and induce apoptosis. The main side effect of using radiation therapy is DNA damage to the surrounding healthy tissues. Hence, protection of non-cancerous tissues against radiation is vital for reducing the side effects [93].

Many of the recent cytoprotective agents capable of protecting normal tissues against radiation-damage have some undesirable and serious side effects that limit their therapeutic applications [94]. However, G. lucidum has been proven to exhibit radio-protective effects in normal cells and enhance the recovery of cellular immune-competence from gamma-irradiation $[95,96]$.

Chen et al. (1995) studied the effect of G. lucidum in repairing the radiation-induced damage in a subset of T-lymphocytes in the spleen of gamma-irradiated mice [97]. The mice were treated with whole body exposure to gamma-irradiation followed by administration of $400 \mathrm{mg} / \mathrm{day} / \mathrm{kg}$ body weight of G. lucidum [97]. This was compared to the control, radiation-treated only mice, as well as radiation-treated mice administered with Krestin, a polysaccharide isolated from the basidomycetes of Coriolus versicolor. Results showed that after 28 days, irradiated mice treated with $G$. lucidum had the highest relative thymus weight with a greater number of CD4 and CD8 splenocytes and an increase in leukocyte counts. This showed that G. lucidum is effective (even more so than Coriolus versicolor extracts) in enhancing the recovery of cellular immunocompetence from gamma-irradiation.

Another study, performed by Pillai et al. (2006), showed that G. lucidum prevents DNA damage induced by radiation. Swiss albino mice, that were exposed to gamma rays and treated with G. lucidum fruiting-body extracts, were evaluated for radio-protective effects [93]. Results 
showed that administration of G. lucidum extract resulted in $90 \%$ protection of plasmid DNA and prevented $98 \%$ of lipid peroxidation. From this study we can conclude that G. lucidum protects the DNA against radiation-induced single-strand breaks and thereby possesses significant radio-protective activity [93].

Cisplatin, the first clinical cancer chemotherapeutic agent belonging to the class of platinumcontaining anti-cancer drugs, is widely used to treat a range of tumours. However, its benefits are counteracted by renal impairment with a decline in glomerular filtration, which is a common side effect of cisplatin [98]. This nephrotoxicity has been thought to be due to the weakening of the renal anti-oxidant defence system. Since G. lucidum has been proven to possess in-vitro antioxidant properties, a study was conducted to examine the prevention of nephrotoxicity induced by the anti-cancer drug cisplatin [99]. Swiss albino mice were treated with fruiting-body extracts of G. lucidum ( 250 and $500 \mathrm{mg} / \mathrm{kg}$ body weight) orally one hour before injecting cisplatin at a high dose (a level commonly used in clinical practice and found to produce nephrotoxicity and cytotoxicity) [99, 100]. Nephrotoxicity was measured by determining the serum creatinine and urea levels and renal anti-oxidant status and results showed that it significantly reduced the elevated serum creatinine and urea levels [99]. Renal anti-oxidant defence system (such as superoxide dismutase, catalase, glutathione peroxidase activities and reduced glutathione) levels following treatment with cisplatin were restored to normal and the therapeutic effects of cisplatin were retained [99].

These studies show that G. lucidum aids in the reduction of toxicities resulting from various popular modes of cancer treatment and could therefore play a major role in combination therapy for cancer treatments.

\section{CONCLUSION:}

Ganderma lucidum has been widely used through the centuries for numerous pharmacological benefits, including immuno-modulating, anti-inflammatory, anti-cancer, anti-diabetic, antioxidative, and radical-scavenging, and anti-aging effects and only in the past two decades has scientific information become available that supports some of these claims. The potency of $G$. lucidum depends chiefly on its chemical constituents, namely the triterpenes and polysaccharides that make up the fruiting body, mycelium or spores. Its anti-cancer properties have been demonstrated in various human and murine cancer cell lines. However, the mechanisms responsible for the anti-cancer effects of $G$. lucidum on cancer cells remain inconclusive. This review paper has identified five potential mechanisms associated with the anti-cancer activities of triterpenes and three for polysaccharides.

Triterpenes have been shown to induce cell cycle arrest at the G1 phase by the downregulation of Cyclin D1, and at the G2 phase by suppressing the activity of PKC. It also induced apoptosis in cancer cell lines via mitochondria-dependent pathways followed by activation of the caspase cascade. Triterpenes also prevented tumour metastasis by regulating MMP and IL- 8 and suppressed inflammatory cytokine secretion in macrophage cells. Lastly, triterpenes were found to act as an anti-oxidant by scavenging free radicals and enhancing innate anti-oxidant enzymes.

Polysaccharides have been shown to enhance the host's immune response by stimulating the production of macrophages, NK cells, and T-lymphocytes. Like triterpenes, polysaccharides can act as an anti-oxidant by reducing oxidative damage induced by ROS and preventing DNA 
strand breaks. It also prevents tumour-derived angiogenesis by reducing the proliferation of HUVEC and by inhibiting the secretion of angiogenic factors such as VEGF and TGF- $\beta 1$.

In conclusion, $G$. lucidum may represent a practical and promising approach for cancer prevention and cancer treatment based on current available data from in vitro and in vivo studies. However, further experimental, epidemiological, and clinical studies need to be carried out to identify other molecular targets; resolve the relationships between G. lucidum intake and cancer risks; and explore the optimum dosing, efficacy, and safety alone and in combination with chemotherapy/radiotherapy. In addition to the anti-cancer activity, G. lucidum has been used for the general promotion of health and longevity. The anti-inflammatory and immune-promoting effects described in this review can potentially facilitate the treatments of other diseases such as arthritis, HIV, and Crohn's disease [1, 101].

\section{List of Abbreviations Used:}

Bad Bcl-2-associated death promoter

Bax Bcl-2-associated $X$ protein

Bcl-2 B-cell lymphoma 2

CDK Cyclin Dependent Kinase

CTL cytotoxic T-lymphocytes

F3 Fraction-3

G. lucidum Ganoderma lucidum

Gl-PP polysaccharide peptide

HUVEC Human umbilical cord vascular endothelial cells

IFN- $\gamma \quad$ interferon- $\gamma$

IL Interleukin

JNK c-Jun N-terminal kinase

LLC Lewis lung carcinoma

MAPK mitogen-activated protein kinases

MHC Major histocompatibility complex

MMP Matrix Metalloproteinase

MPO myeloperoxidase

NK natural killer

PKC protein kinase $\mathrm{C}$

ROS reactive oxygen species

TGF Transforming Growth Factor

TNF tumour necrosis factor

VEGF vascular endothelial growth factor

WEES-G6 triterpene-enriched ethanol soluble fractions

Competing interests: The authors are aware of no competing interests

Authors' contributions: All authors contributed to the planning and writing of this paper. 
Acknowledgements and funding: The authors acknowledge the University of Auckland for providing access to the resources necessary for the completion of this review.

\section{REFERENCES:}

1. Sanodiya BS, Thakur GS, Baghel RK, Prasad GB, Bisen PS: Ganoderma lucidum: a potent pharmacological macrofungus. Curr Pharm Biotechnol. 2009, 10(8):717-742.

2. Mau JL, Lin HC, Chen CC: Non-volatile components of several medicinal mushrooms. Food Research International. 2001, 34(6):521-526.

3. Boh B, Berovic M, Zhang J, Zhi-Bin L: Ganoderma lucidum and its pharmaceutically active compounds. Biotechnol Annu Rev. 2007, 13:265-301.

4. Zhou XW, Lin J, Yin YZ, Zhao JY, Sun XF, Tang KX: Ganodermataceae: Natural products and their related pharmacological functions. American Journal of Chinese Medicine. 2007, 35(4):559-574.

5. Yuen JW, Gohel MD: Anticancer effects of Ganoderma lucidum: a review of scientific evidence. Nutr Cancer. 2005, 53(1):11-17.

6. Shi L, Ren A, Mu D, Zhao M: Current progress in the study on biosynthesis and regulation of ganoderic acids. Appl Microbiol Biotechnol. 2010, 88(6):1243-1251.

7. Haralampidis K, Trojanowska M, Osbourn AE: Biosynthesis of triterpenoid saponins in plants. Adv Biochem Eng Biotechnol. 2002, 75:31-49.

8. Yue QX, Song XY, Ma C, Feng LX, Guan SH, Wu WY, Yang M, Jiang BH, Liu X, Cui YJ, Guo DA: Effects of triterpenes from Ganoderma lucidum on protein expression profile of HeLa cells. Phytomedicine : international journal of phytotherapy and phytopharmacology. 2010, 17(8-9):606-613.

9. Su CH, Yang YZ, Ho HO, Hu CH, Sheu MT: High-performance liquid chromatographic analysis for the characterization of triterpenoids from Ganoderma. J Chromatogr Sci. 2001, 39(3):93-100.

10. Chen NH, Liu JW, Zhong JJ: Ganoderic acid T inhibits tumor invasion in vitro and in vivo through inhibition of MMP expression. Pharmacol Rep. 2010, 62(1):150-163.

11. Tang W, Liu JW, Zhao WM, Wei DZ, Zhong JJ: Ganoderic acid T from Ganoderma lucidum mycelia induces mitochondria mediated apoptosis in lung cancer cells. Life Sci. 2006, 80(3):205-211.

12. Xu K, Liang X, Gao F, Zhong J, Liu J: Antimetastatic effect of ganoderic acid T in vitro through inhibition of cancer cell invasion. Process Biochemistry. 2010, 45(8):1261-1267.

13. Yue QX, Cao ZW, Guan SH, Liu XH, Tao L, Wu WY, Li YX, Yang PY, Liu X, Guo DA: Proteomics characterization of the cytotoxicity mechanism of ganoderic acid D and computer-automated estimation of the possible drug target network. Mol Cell Proteomics. 2008, 7(5):949-961.

14. Chang UM, Li CH, Lin LI, Huang CP, Kan LS, Lin SB: Ganoderiol F, a ganoderma triterpene, induces senescence in hepatoma HepG2 cells. Life sciences. 2006, 79(12):1129-1139.

15. Min BS, Gao JJ, Nakamura N, Hattori M: Triterpenes from the spores of Ganoderma lucidum and their cytotoxicity against meth-A and LLC tumor cells. Chemical \& pharmaceutical bulletin. 2000, 48(7):1026-1033. 
16. Gao JJ, Min BS, Ahn EM, Nakamura N, Lee HK, Hattori M: New triterpene aldehydes, lucialdehydes A-C, from Ganoderma lucidum and their cytotoxicity against murine and human tumor cells. Chemical \& pharmaceutical bulletin. 2002, 50(6):837-840.

17. Gao JJ, Hirakawa A, Min BS, Nakamura N, Hattori M: In vivo antitumor effects of bitter principles from the antlered form of fruiting bodies of Ganoderma lucidum. Journal of Natural Medicines. 2006, 60(1):42-48.

18. Guan SH, Xia JM, Yang M, Wang XM, Liu X, Guo DA: Cytotoxic lanostanoid triterpenes from Ganoderma lucidum. Journal of Asian natural products research. 2008, 10(7-8):705-710.

19. Niu XM, Li SH, Xiao WL, Sun HD, Che CT: Two new lanostanoids from Ganoderma resinaceum. Journal of Asian natural products research. 2007, 9(6-8):659-664.

20. Patra N, De U, Kang JA, Kim JM, Ahn MY, Lee J, Jung JH, Chung HY, Moon HR, Kim HS: A novel epoxypropoxy flavonoid derivative and topoisomerase II inhibitor, MHY336, induces apoptosis in prostate cancer cells. Eur J Pharmacol. 2011, 658(23):98-107.

21. Wu G, Qian Z, Guo J, Hu D, Bao J, Xie J, Xu W, Lu J, Chen X, Wang Y: Ganoderma lucidum Extract Induces G1 Cell Cycle Arrest, and Apoptosis in Human Breast Cancer Cells. Am J Chin Med. 2012, 40(3):631-642.

22. Jedinak A, Thyagarajan-Sahu A, Jiang J, Sliva D: Ganodermanontriol, a lanostanoid triterpene from Ganoderma lucidum, suppresses growth of colon cancer cells through sscatenin signaling. Int J Oncol. 2011, 38(3):761-767.

23. Shtutman M, Zhurinsky J, Simcha I, Albanese C, D'amico M, Pestell R, Ben-Ze'ev A: The cyclin D1 gene is a target of the beta-catenin/LEF-1 pathway. Proc Natl Acad Sci U S A. 1999, 96(10):5522-5527.

24. Yan YX, Nakagawa H, Lee MH, Rustgi AK: Transforming growth factor-alpha enhances cyclin D1 transcription through the binding of early growth response protein to a cisregulatory element in the cyclin D1 promoter. J Biol Chem. 1997, 272(52):33181-33190.

25. Tetsu O, Mccormick F: Beta-catenin regulates expression of cyclin D1 in colon carcinoma cells. Nature. 1999, 398(6726):422-426.

26. Bartkova J, Lukas J, Strauss M, Bartek J: The PRAD-1/cyclin D1 oncogene product accumulates aberrantly in a subset of colorectal carcinomas. Int J Cancer. 1994, 58(4):568-573.

27. Lin SB, Li CH, Lee SS, Kan LS: Triterpene-enriched extracts from Ganoderma lucidum inhibit growth of hepatoma cells via suppressing protein kinase $\mathrm{C}$, activating mitogenactivated protein kinases and G2-phase cell cycle arrest. Life Sci. 2003, 72(21):23812390.

28. Thompson LJ, Fields AP: betaII protein kinase $\mathrm{C}$ is required for the $\mathrm{G} 2 / \mathrm{M}$ phase transition of cell cycle. J Biol Chem. 1996, 271(25):15045-15053.

29. Fishman DD, Segal S, Livneh E: The role of protein kinase C in G1 and G2/M phases of the cell cycle (review). Int J Oncol. 1998, 12(1):181-186.

30. Arita Y, Buffolino P, Coppock DL: Regulation of the cell cycle at the G2/M boundary in metastatic melanoma cells by 12-O-tetradecanoyl phorbol-13-acetate (TPA) by blocking p34cdc2 kinase activity. Exp Cell Res. 1998, 242(2):381-390. 
31. Hofmann J, O'connor PM, Jackman J, Schubert C, Ueberall F, Kohn KW, Grunicke H: The protein kinase C inhibitor ilmofosine (BM 41 440) arrests cells in G2 phase and suppresses CDC2 kinase activation through a mechanism different from that of DNA damaging agents. Biochem Biophys Res Commun. 1994, 199(2):937-943.

32. Johnson GL, Lapadat R: Mitogen-activated protein kinase pathways mediated by ERK, JNK, and p38 protein kinases. Science. 2002, 298(5600):1911-1912.

33. Liu Y, Guyton KZ, Gorospe M, Xu Q, Lee JC, Holbrook NJ: Differential activation of ERK, JNK/SAPK and P38/CSBP/RK map kinase family members during the cellular response to arsenite. Free Radic Biol Med. 1996, 21(6):771-781.

34. Price MA, Cruzalegui FH, Treisman R: The p38 and ERK MAP kinase pathways cooperate to activate Ternary Complex Factors and c-fos transcription in response to UV light. EMBO J. 1996, 15(23):6552-6563.

35. Li CH, Chen PY, Chang UM, Kan LS, Fang WH, Tsai KS, Lin SB: Ganoderic acid X, a lanostanoid triterpene, inhibits topoisomerases and induces apoptosis of cancer cells. Life sciences. 2005, 77(3):252-265.

36. Jiang J, Slivova V, Harvey K, Valachovicova T, Sliva D: Ganoderma lucidum suppresses growth of breast cancer cells through the inhibition of Akt/NF-kappaB signaling. Nutr Cancer. 2004, 49(2):209-216.

37. Fukuzawa M, Yamaguchi R, Hide I, Chen Z, Hirai Y, Sugimoto A, Yasuhara T, Nakata Y: Possible involvement of long chain fatty acids in the spores of Ganoderma lucidum (Reishi Houshi) to its anti-tumor activity. Biol Pharm Bull. 2008, 31(10):1933-1937.

38. Liu RM, Zhong JJ: Ganoderic acid Mf and S induce mitochondria mediated apoptosis in human cervical carcinoma HeLa cells. Phytomedicine : international journal of phytotherapy and phytopharmacology. 2011, 18(5):349-355.

39. Liu RM, Li YB, Zhong JJ: Cytotoxic and pro-apoptotic effects of novel ganoderic acid derivatives on human cervical cancer cells in vitro. Eur J Pharmacol. 2012, 681(1-3):2333.

40. Green DR, Reed JC: Mitochondria and apoptosis. Science. 1998, 281(5381):1309-1312.

41. Green D, Kroemer G: The central executioners of apoptosis: caspases or mitochondria? Trends in cell biology. 1998, 8(7):267-271.

42. Liu RM, Zhong JJ: Ganoderic acid Mf and S induce mitochondria mediated apoptosis in human cervical carcinoma HeLa cells. Phytomedicine. 2011, 18(5):349-355.

43. Zimmermann KC, Green DR: How cells die: apoptosis pathways. The Journal of allergy and clinical immunology. 2001, 108(4 Suppl):S99-103.

44. Zong WX, Li C, Hatzivassiliou G, Lindsten T, Yu QC, Yuan J, Thompson CB: Bax and Bak can localize to the endoplasmic reticulum to initiate apoptosis. J Cell Biol. 2003, 162(1):59-69.

45. Tzivion G, Gupta VS, Kaplun L, Balan V: 14-3-3 proteins as potential oncogenes. Seminars in cancer biology. 2006, 16(3):203-213.

46. Masters SC, Yang H, Datta SR, Greenberg ME, Fu H: 14-3-3 inhibits Bad-induced cell death through interaction with serine-136. Molecular pharmacology. 2001, 60(6):13251331. 
47. Bielawski K, Bielawska A, Slodownik T, Bolkun-Skornicka U, Muszynska A: Prolinelinked nitrosoureas as prolidase-convertible prodrugs in human breast cancer cells. Pharmacological reports : PR. 2008, 60(2):171-182.

48. Chen NH, Liu JW, Zhong JJ: Ganoderic acid Me inhibits tumor invasion through downregulating matrix metalloproteinases $2 / 9$ gene expression. Journal of pharmacological sciences. 2008, 108(2):212-216.

49. Chen NH, Liu JW, Zhong JJ: Ganoderic acid T inhibits tumor invasion in vitro and in vivo through inhibition of MMP expression. Pharmacological reports : PR. 2010, 62(1):150-163.

50. Brown NS, Jones A, Fujiyama C, Harris AL, Bicknell R: Thymidine phosphorylase induces carcinoma cell oxidative stress and promotes secretion of angiogenic factors. Cancer Res. 2000, 60(22):6298-6302.

51. Freund A, Chauveau C, Brouillet JP, Lucas A, Lacroix M, Licznar A, Vignon F, Lazennec G: IL-8 expression and its possible relationship with estrogen-receptornegative status of breast cancer cells. Oncogene. 2003, 22(2):256-265.

52. Bendre MS, Gaddy-Kurten D, Mon-Foote T, Akel NS, Skinner RA, Nicholas RW, Suva LJ: Expression of interleukin 8 and not parathyroid hormone-related protein by human breast cancer cells correlates with bone metastasis in vivo. Cancer research. 2002, 62(19):5571-5579.

53. Thyagarajan A, Jiang J, Hopf A, Adamec J, Sliva D: Inhibition of oxidative stressinduced invasiveness of cancer cells by Ganoderma lucidum is mediated through the suppression of interleukin-8 secretion. Int J Mol Med. 2006, 18(4):657-664.

54. Birbach A, Eisenbarth D, Kozakowski N, Ladenhauf E, Schmidt-Supprian M, Schmid JA: Persistent inflammation leads to proliferative neoplasia and loss of smooth muscle cells in a prostate tumor model. Neoplasia. 2011, 13(8):692-703.

55. De Marzo AM, Platz EA, Sutcliffe S, Xu J, Gronberg H, Drake CG, Nakai Y, Isaacs WB, Nelson WG: Inflammation in prostate carcinogenesis. Nat Rev Cancer. 2007, 7(4):256269.

56. Lin CY, Lin CJ, Chen KH, Wu JC, Huang SH, Wang SM: Macrophage activation increases the invasive properties of hepatoma cells by destabilization of the adherens junction. FEBS Lett. 2006, 580(13):3042-3050.

57. Kimura YN, Watari K, Fotovati A, Hosoi F, Yasumoto K, Izumi H, Kohno K, Umezawa K, Iguchi H, Shirouzu K, Takamori S, Kuwano M, Ono M: Inflammatory stimuli from macrophages and cancer cells synergistically promote tumor growth and angiogenesis. Cancer Sci. 2007, 98(12):2009-2018.

58. Dudhgaonkar S, Thyagarajan A, Sliva D: Suppression of the inflammatory response by triterpenes isolated from the mushroom Ganoderma lucidum. Int Immunopharmacol. 2009, 9(11):1272-1280.

59. Dreher D, Junod AF: Role of oxygen free radicals in cancer development. Eur J Cancer. 1996, 32A(1):30-38.

60. Sun J, Chu YF, Wu X, Liu RH: Antioxidant and antiproliferative activities of common fruits. J Agric Food Chem. 2002, 50(25):7449-7454. 
61. Smina TP, Mathew J, Janardhanan KK, Devasagayam TP: Antioxidant activity and toxicity profile of total triterpenes isolated from Ganoderma lucidum (Fr.) P. Karst occurring in South India. Environ Toxicol Pharmacol. 2011, 32(3):438-446.

62. Smina TP, De S, Devasagayam TP, Adhikari S, Janardhanan KK: Ganoderma lucidum total triterpenes prevent radiation-induced DNA damage and apoptosis in splenic lymphocytes in vitro. Mutat Res. 2011, 726(2):188-194.

63. Chan W, Law H, Lin Z, Lau Y, Chan G: Response of human dendritic cells to different immunomodulatory polysaccharides derived from mushroom and barley. International Immunology. 2007, 19(7):891-899.

64. Sone Y, Okuda R, Wada N, Kishida E, Misaki A: Structure and antitumor activities of polysaccharides isolated from fruiting body and the growing culture of mycelium of Ganoderma lucidum. Agric Biol Chem. 1985, 49:2641-2653.

65. Upton R, Pharmacopoeia AH. Reishi Mushroom: Ganoderma Lucidum : Standards of Analysis, Quality Control, and Therapeutics: American Herbal Pharmacopoeia; 2000.

66. Chen WC, Hau DM, Lee SS: Effects of Ganoderma-Lucidum and Krestin on Cellular Immunocompetence in Gamma-Ray-Irradiated Mice. American Journal of Chinese Medicine. 1995, 23(1):71-80.

67. Lieu CW, Lee SS, Wang SY: The Effect of Ganoderma-Lucidum on Induction of Differentiation in Leukemic U937-Cells. Anticancer Research. 1992, 12(4):1211-1216.

68. Wang SY, Hsu ML, Hsu HC, Tzeng CH, Lee SS, Shiao MS, Ho CK: The anti-tumor effect of Ganoderma lucidum is mediated by cytokines released from activated macrophages and T lymphocytes. International Journal of Cancer. 1997, 70(6):699-705.

69. Chang ST. Mushrooms cultivation, nutritional value, medicinal effect, and environmental impact. Miles PG, Chang ST, editors. Boca Raton, Fla.: Boca Raton, Fla: CRC Press; 2004.

70. Bach JP, Deuster O, Balzer-Geldsetzer M, Meyer B, Dodel R, Bacher M: The Role of Macrophage Inhibitory Factor in Tumorigenesis and Central Nervous System Tumors. Cancer. 2009, 115(10):2031-2040.

71. Mantovani A, Sica A: Macrophages, innate immunity and cancer: balance, tolerance, and diversity. Current Opinion in Immunology. 2010, 22(2):231-237.

72. Zhang J, Tang Q, Zhou C, Jia W, Da Silva L, Nguyen LD, Reutter W, Fan H: GLIS, a bioactive proteoglycan fraction from Ganoderma lucidum, displays anti-tumour activity by increasing both humoral and cellular immune response. Life sciences. 2010, 87(1922):628-637.

73. Hewitt EW: The MHC class I antigen presentation pathway: strategies for viral immune evasion. Immunology. 2003, 110(2):163-169.

74. Gebhard B, Schutz G, Ecker RC, Steiner GE, Rudas M, Gnant M, Oehler R: MHC-class-I expression in human breast cancer correlates with nuclear localization of the $90 \mathrm{kDa}$ heat-shock-protein. Anticancer research. 1999, 19(6B):5293-5297.

75. Kijima M, Saio M, Oyang GF, Suwa T, Miyauchi R, Kojima Y, Imai H, Nakagawa J, Nonaka K, Umemura N, Nishimura T, Takami T: Natural killer cells play a role in MHC class I in vivo induction in tumor cells that are MHC negative in vitro. International journal of oncology. 2005, 26(3):679-684. 
76. Wang YY, Khoo KH, Chen ST, Lin CC, Wong CH, Lin CH: Studies on the immunomodulating and antitumor activities of Ganoderma lucidum (Reishi) polysaccharides: Functional and proteomic analyses of a fucose-containing glycoprotein fraction responsible for the activities. Bioorganic \& Medicinal Chemistry. 2002, 10(4):1057-1062.

77. Chien CA, Cheng JL, Chang WT, Tien MH, Tsao CM, Chang YH, Chang HY, Hsieh JF, Wong $\mathrm{CH}$, Chen ST: Polysaccharides of Ganoderma lucidum alter cell immunophenotypic expression and enhance CD56(+) NK-cell cytotoxicity in cord blood. Bioorganic \& Medicinal Chemistry. 2004, 12(21):5603-5609.

78. Hsu JW, Huang HC, Chen ST, Wong CH, Juan HF: Ganoderma lucidum Polysaccharides Induce Macrophage-Like Differentiation in Human Leukemia THP-1 Cells via Caspase and p53 Activation. Evid Based Complement Alternat Med. 2011, 2011:358717.

79. Lin KM, Austin GE: Functional activity of three distinct myeloperoxidase (MPO) promoters in human myeloid cells. Leukemia. 2002, 16(6):1143-1153.

80. Lu HM, Uesaka T, Katoh O, Kyo E, Watanabe H: Prevention of the development of preneoplastic lesions, aberrant crypt foci, by a water-soluble extract from cultured medium of Ganoderma lucidum (Rei-shi) mycelia in male F344 rats. Oncol Rep. 2001, 8(6):1341-1345.

81. Lu H, Kyo E, Uesaka T, Katoh O, H. W: A water-soluble extract from cultured medium of Ganoderma lucidum (Rei-shi) mycelia suppresses azoxymethane-induction of colon cancers in male F344 rats. Oncol Rep. 2003, 10(2):375-379.

82. Lee JM, Kwon H, Jeong H, Lee JW, Lee SY, Baek SJ, Surh YJ: Inhibition of lipid peroxidation and oxidative DNA damage by Ganoderma lucidum. Phytother Res. 2001, 15(3):245-249.

83. Song YS, Kim SH, Sa JH, Jin C, Lim CJ, Park EH: Anti-angiogenic and inhibitory activity on inducible nitric oxide production of the mushroom Ganoderma lucidum. Journal of ethnopharmacology. 2004, 90(1):17-20.

84. Cao QZ, Lin ZB: Ganoderma lucidum polysaccharides peptide inhibits the growth of vascular endothelial cell and the induction of VEGF in human lung cancer cell. Life Sciences. 2006, 78(13):1457-1463.

85. Stanley G, Harvey K, Slivova V, Jiang J, Sliva D: Ganoderma lucidum suppresses angiogenesis through the inhibition of secretion of VEGF and TGF-beta1 from prostate cancer cells. Biochemical and biophysical research communications. 2005, 330(1):46-52.

86. Ruhan Askin MS, And Motonobu Goto*: Extraction of bioactive compounds from Ganoderma Lucidum. Department of Applied Chemistry and Biochemistry, Kumamoto University. 2008.

87. Zhou XW, Su KQ, Zhang YM: Applied modern biotechnology for cultivation of Ganoderma and development of their products. Applied Microbiology and Biotechnology. 2012, 93(3):941-963.

88. Huang SQ, Li JW, Wang Z, Pan HX, Chen JX, Ning ZX: Optimization of Alkaline Extraction of Polysaccharides from Ganoderma lucidum and Their Effect on Immune Function in Mice. Molecules. 2010, 15(5):3694-3708.

89. Gao Y, Zhou S: Cancer Prevention and Treatment by Ganoderma, a Mushroom with Medicinal Properties. Food Reviews International. 2003, 19(3):275-325. 
90. Gao Y, Zhang R, Zhang J, Gao S, Gao W, Zhang H, Wang H, Han B: Study of the extraction process and in vivo inhibitory effect of ganoderma triterpenes in oral mucosa cancer. Molecules. 2011, 16(7):5315-5332.

91. Lu QY, Jin YS, Zhang QF, Zhang ZF, Heber D, Go VLW, Li FP, Rao JY: Ganoderma lucidum extracts inhibit growth and induce actin polymerization in bladder cancer cells in vitro. Cancer Lett. 2004, 216(1):9-20.

92. Tong CC, Choong YK, Umar NaB, Noordin MM, Mohamed S: Cytotoxic activity induced by crude extracts of Ganoderma lucidum (W. Curt.: Fr.) P. Karst. on mouse myeloma cancer cell-line. World Journal of Microbiology \& Biotechnology. 2009, 25(4):687-695.

93. Pillai TG, Savi VP, Maurya DK, Nair CKK, Janardhanan KK: Prevention of radiationinduced damages by aqueous extract of Ganoderma lucidum occurring in southern parts of India. Current Science. 2006, 91(3):341-344.

94. Smina TP, Mathew J, Janardhanan KK, Deuasagayam TPA: Antioxidant activity and toxicity profile of total triterpenes isolated from Ganoderma lucidum (Fr.) P. Karst occurring in South India. Environmental Toxicology and Pharmacology. 2011, 32(3):438-446.

95. Chen WC, Hau DM: Effects of Ganoderma-Lucidum on Cellular Immunocompetence in Gamma-Irradiated Mice. Phytotherapy Research. 1995, 9(7):533-535.

96. Smina TP, De S, Devasagayam TPA, Adhikari S, Janardhanan KK: Ganoderma lucidum total triterpenes prevent radiation-induced DNA damage and apoptosis in splenic lymphocytes in vitro. Mutation Research-Genetic Toxicology and Environmental Mutagenesis. 2011, 726(2):188-194.

97. Chen WC, Hau DM, Wang CC, Lin IH, Lee SS: Effects of Ganoderma-Lucidum and Krestin on Subset T-Cell in Spleen of Gamma-Irradiated Mice. American Journal of Chinese Medicine. 1995, 23(3-4):289-298.

98. Hamdi T, Latta S, Jallad B, Kheir F, Alhosaini MN, Patel A: Cisplatin-Induced Renal Salt Wasting Syndrome. Southern Medical Journal. 2010, 103(8):793-799.

99. Sheena N, Ajith TA, Janardhanan KK: Prevention of nephrotoxicity induced by the anticancer drug cisplatin, using Ganoderma lucidum, a medicinal mushroom occurring in South India. Current Science. 2003, 85(4):478-482.

100. Somani SM, Husain K, Whitworth C, Trammell GL, Malafa M, Rybak LP: Dosedependent protection by lipoic acid against cisplatin-induced nephrotoxicity in rats: Antioxidant defense system. Pharmacology \& Toxicology. 2000, 86(5):234-241.

101. Hanaoka R, Ueno Y, Tanaka S, Nagai K, Onitake T, Yoshioka K, Chayama K: The water-soluble extract from cultured medium of Ganoderma lucidum (Reishi) mycelia (Designated as MAK) ameliorates murine colitis induced by trinitrobenzene sulphonic acid. Scand J Immunol. 2011, 74(5):454-462. 